\title{
Movement of leopard tortoises in response to environmental and climatic variables in a semi-arid environment
}

\author{
Martyn Drabik-Hamshare and Colleen T. Downs ${ }^{*}$
}

\begin{abstract}
Background: Tortoises (Testudinidae) occur in a wide range of environments, providing important ecosystem functions, such as seed dispersal and refuge in the form of burrows. Tortoise movement has previously been shown to be related to resource availability, reproductive status and local environmental conditions. However, understanding of the variables that drive their movement remains comparatively low. We investigated aspects of movement in leopard tortoises Stigmochelys pardalis — the largest and most abundant tortoise species in sub-Saharan Africa-in response to environmental, climatic and individual variables in the semi-arid Karoo, South Africa. We used GPS telemetry to calculate bihourly and daily movement and used generalized linear mixed models (GLMMs) to ascertain important predictor variables.

Results: Temperature, distance from water sources, and month were important variables for predicting both bihourly and daily movement. Our results showed that movement increased when individuals were close to known water sources, indicating that individuals close to water resources make regular long distance movements. Movement showed a positive relationship for temperature in both models, whilst rainfall was an important predictor for bihourly movement. Our results displayed aspects of seasonality, with movement highest in spring months, likely related to reproductive activities, although no sex differences were observed.

Conclusions: We identified temporal and spatial conditions in which leopard tortoise movement increased. Our results further support the relationship between water as a resource and movement in leopard tortoises. Individuals used one of two basic movement behaviours in relation to water in this water scarce environment. Either an individual's home range and movements included permanent water resources allowing internal water storage replenishment, or excluded these with reliance on food resources (such as grasses, forbs, and succulents) for water.
\end{abstract}

Keywords: Spatial ecology, Water loss, Karoo, Stigmochelys pardalis, Environmental variables, Electric fencing

\section{Background}

Continual growth of human population increases the need to harvest and distribute essential resources, causing modifications to environments, and subsequent disturbance and contamination of local ecosystems [1]. Such land use change is a primary cause for damage to ecosystems and animal populations [2], as it directly relates to habitat loss, habitat defragmentation, and global warming [3]. It is of great importance to conduct systematic research with regards to potential effects of land use change, in order to

\footnotetext{
* Correspondence: downs@ukzn.ac.za

School of Life Sciences, University of KwaZulu-Natal, Private Bag X01, Scottsville, Pietermaritzburg, KwaZulu-Natal 3209, South Africa
}

produce effective decision-making and management for protection and conservation of endangered and threatened species and habitats. Land use change in the Central Karoo over the last few centuries has greatly affected animal populations, with the vast majority of pre-existing lands now converted to private commercial farming. Introduction of livestock, building of roads and fences, and reliance of animal and human communities on already depleted water supplies, has negatively affected many animal and plant species. For example, wattled cranes (Bugeranus carunculatus), southern bald ibis (Geronticus calvus), and Cape vultures (Gyps coprotheres)-regionally common before the arrival of Europeans (c. 1650)-are now all but extinct regionally, partly due to changes in availability of water and 
natural food resources [4-6]. Changes in land use in the Karoo are expected to continue with the introduction of hydraulic fracturing (fracking) activities: a process whereby fuel is extracted from deep within the Earth's surface following the injection of a highly pressurised liquid fluid [7]. Fracking operations are expected before end of 2017 [8,9], despite worries about impacts on human and animal communities due to increasing water salinity and altering water quality through accidental release of water runoff $[10,11]$.

The Karoo is an important ecosystem, as it is seen as a centre for endemism in birds and reptiles [12, 13]. For example, of the 18 tortoise species in sub-Saharan Africa, at least eight species occur somewhere in the Karoo: up to five sympatrically [14-16]. Tortoises are of the most threatened animals, with as many as $80 \%$ classified at least as 'Vulnerable', and $47 \%$ at least as 'Endangered' by the International Union for the Conservation of Nature (IUCN) [14, 17]. The importance of tortoises to their environments is increasingly being understood. Tortoises provide an important ecosystem function in the form of seed dispersal $[18,19]$ promoted by periodical long distance movement and long gut retention time [20]. This function is particularly importance in xeric areas where natural herbivores are no longer present. Tortoises are considered keystone species in some regions. For example, burrowing species such as Gopherus spp. produce refugia used by multiple species to escape harsh environmental conditions [21]. It is important to improve understanding of tortoise spatial ecology.

Tortoises are able to tolerate imbalances in regards to their water:electrolyte ratio [22, 23], allowing a greater ability to survive drought conditions [23, 24]. However, drinking water remains necessary to facilitate urination to remove waste products, which otherwise can cause severe stress and mortality [24]. Several studies investigating spatial ecology of tortoises have identified the positive relationship between movement and water (e.g. permanent water sources or rainfall) with movement typically increased after periods of higher rainfall [22, 25-29]. Increased tortoise movement has also been related to higher temperatures [30, 31], seasonality (e.g. higher in spring) [31-34], and reproductive status (search for mates, egglaying habitat and resources to feed increased energy demand) [32, 35-38]. Resource availability also appears to be of importance. For example, distribution and movement in Aldabra tortoises (Aldabrachelys gigantea) appears to be related to resources [39], whilst the Santa Cruz giant tortoise of the Galápagos archipelago (Chelonoidis nigra) undertakes seasonal altitudinal migrations in response to vegetation dynamics [40]. In contrast, most other tortoise species maintain home ranges, instead modifying home range size in response to resource availability $[22,34]$. Further information is required to better understand interactions between tortoises and environmental conditions.

The leopard tortoise (Stigmochelys pardalis) is the largest tortoise species in sub-Saharan Africa, inhabiting a wide range of environmental conditions across the eastern and southern parts of the continent $[14,15]$. The species is currently classified by IUCN as 'Least Concern' $[14,36]$, though they appear to be particularly vulnerable to electric fencing, which is common in Karoo farms to control predation on livestock by caracal (Caracal caracal) and black-backed jackal (Canis mesomelas) [41]. Previous leopard tortoise research has shown great variability in movement distances and home range sizes, likely related to seasonal temperature, food availability, rainfall, mean body mass, and access to other important resources [31, 33, 42]. For example, leopard tortoises were shown to move much larger distances in the Nama-Karoo (up to $8 \mathrm{~km}$ per day) [33]-even displaying nomadic behaviour in some cases [26] — when compared with populations in valley thicket (up to $100 \mathrm{~m}$ per day) [43] and Swaziland (about $50 \mathrm{~m}$ per day) [31]. Karoo leopard tortoises also have larger home range sizes, using areas upwards of 200 ha [33] compared with valley thicket (57.56 ha) and Swaziland (13.49 ha). These studies suggest that movement and home range is higher in areas where resource availability (e.g. food, water, and mates) is decreased. Despite several studies investigating movement of leopard tortoises, information on drivers of movement and habitat use is not fully understood.

Geolocation information helps to understand species interactions, identify important habitats, and quantify the relationship between behaviour and climatic and environmental variables [44]. Improving knowledge of spatial ecology is important to identify biotic and abiotic effects relating to land use, and to guide successful management decisions for species conservation [45]. Global positioning system (GPS) transmitters were deployed on ten wild-caught individuals. We set out to further investigate spatial ecology of leopard tortoises, to a) provide details on movement distances in relation to climatic, environmental and sex variables, and b) highlight importance of water and food resources.

We predicted higher movement closer to important resources (e.g. food and water), as previous studies have shown increased activity when resources are abundant [22]. We predicted climatic variables (temperature and rainfall) would positively influence movement, as higher temperatures causes increased metabolic rates; whilst tortoises are expected to seek natural water sources after rain events [22, 28]. Finally, we expected tortoises would make larger movements during the breeding season (September to November), as mate-searching, egg-laying, and associated increases in energy demand is increased 
$[46,47]$. However, given leopard tortoises can occur at very low densities (0.017 tortoises per ha) [25], we expected mate-searching behaviour by males would produce higher movements overall.

\section{Methods}

\section{Study area}

The semi-arid Karoo covers much of the Northern, Western and Eastern Cape Provinces of South Africa, covering an area of approximately 37 million ha [48]. Northern and western parts of the Karoo are typically arid, though even in eastern semi-arid areas, rainfall is both unpredictable and unreliable $[49,50]$. During summer, daily temperatures of more than $30{ }^{\circ} \mathrm{C}$ are regularly recorded [49], whilst severe frost events also occur [51]. Plants in the region have adapted to such conditions-hairy cuticles, tannins and phenolic compounds [52] - to cope with severe stress and desiccation $[48,49,53]$. Due to common weather conditions, vegetation of the Central Karoo is highly homogenous with typically low levels of endemism [54].

The study was carried out on three private mixed livestock commercial farms in the Central Karoo, Western Cape Province, South Africa (Fig. 1). The farms used were Baakensrug, Kamferskraal, and Elandsfontein (approximately $32^{\circ} 15 \mathrm{~S}, 23^{\circ} \mathrm{E}$ ), which are part of the Nelspoort and Beaufort West communities. Each farm utilises aspects of holistic resource management, with rotational grazing of mixed livestock to reduce selective grazing and subsequent desertification [55]. Private hunting of freeroaming game is also present. Whilst the three farms are connected, roads, fences and mountain ranges form distinct boundaries (unpublished observations). These farms use various agricultural fencing to separate pastures of varying sizes and protect livestock. These fences have varying levels of restriction and risk to tortoises; from little (e.g. low tensile wire fence) to full (e.g. chain-link fence). In some areas, farms also use electric fencing to prevent animals digging under agricultural fencing. These electric fences present a major mortality risk for tortoises $[56,57]$.

\section{Fieldwork}

As tortoises generally have a bimodal activity pattern, especially in spring and summer [28, 58, 59], wildcaught adult leopard tortoises were located by walking $2 \mathrm{~km}$ transects $(n=20)$ in mornings and evenings in November and December 2014. Transect locations on farms were determined using random points in ArcGIS 10.3.1 (ESRI, CA, USA). Upon locating each individual, digital hanging scales (Pesola, Schindellegi, Switzerland) were used to measure body mass (g).

Unique GPS-Global System for Mobile Communications (GSM)/Ultra High Frequency (UHF) transmitters (Wireless Wildlife, Pretoria, South Africa) were initially placed on adult leopard tortoises $(n=10)$. Care was taken to avoid placing transmitters across scutes to avoid problems relating to growth. Tortoises were selected based on body mass (mean: $13.92 \mathrm{~kg}$, range: 7.43 to $26.27 \mathrm{~kg}$ ) and sex. We determined sex of individuals based on plastral concavity, tail length, and shapes of anal scutes and supracaudal shield [60,61]. The transmitter was placed appropriately on the carapace to avoid inhibiting potential mating events (e.g. front of carapace for females) using dental acrylic. Mass of transmitters $(74 \mathrm{~g})$ was much lower (range: 0.3 to $1.0 \%$ ) than the suggested $5 \%$ body mass [62]. Transmitters were programmed to receive bihourly geolocation data for a minimum period of 12 months, based on expected internal battery life. Individuals were released at initial point of location within $30 \mathrm{~min}$.

In order to download telemetry data, the study area was revisited four times (approximately every 3 months) throughout 2015. A base-station was used to communicate with the transmitters to download internally-stored data. The base-station was positioned at high elevations, as direct 'line-of-sight' between base-station and transmitters was required. Once downloaded, the base-station sent data via a local cell-phone network. Raw telemetry data were downloaded as a CSV file via Wireless Wildlife [63]. On each visit, attempts were made to physically locate telemetered individuals to assess condition of each tortoise, using recently downloaded data. Whilst no body condition index was used, we assessed condition based on levels of activity, general well-being, and changes to body mass. In cases where individuals could not be physically located, condition was assessed based on recent movement data via Wireless Wildlife. One individual (LPD006) was found to have died for unknown causes in February 2015 after only 88 days. The transmitter was redeployed on a new leopard tortoise individual.

\section{Climatic variables}

Hourly temperature and rainfall data were collected from the South African Weather Service (Pretoria, South Africa) [64], using Beaufort-West weather station (station number: 00920815 ), approximately $45 \mathrm{~km}$ west of study sites. Data were collected from September 1993 to end of study period (December 2015) to compare study period to previous years. Mean temperature and total rainfall $(\mathrm{mm})$ were collected for three temporal scales for the study period: bihourly and daily for movement analysis, and monthly for long-term data comparisons.

\section{Data screening}

Screening of data were carried out to discard incorrect location fixes using 'adehabitatLT' version 0.3.20, 'adehabitatMA' version 0.3 .10 , 'ade4' version 1.7-4 and 'sp' version $1.2-3$ in $\mathrm{R}$ version 3.1.2 [65, 66], using RStudio version 


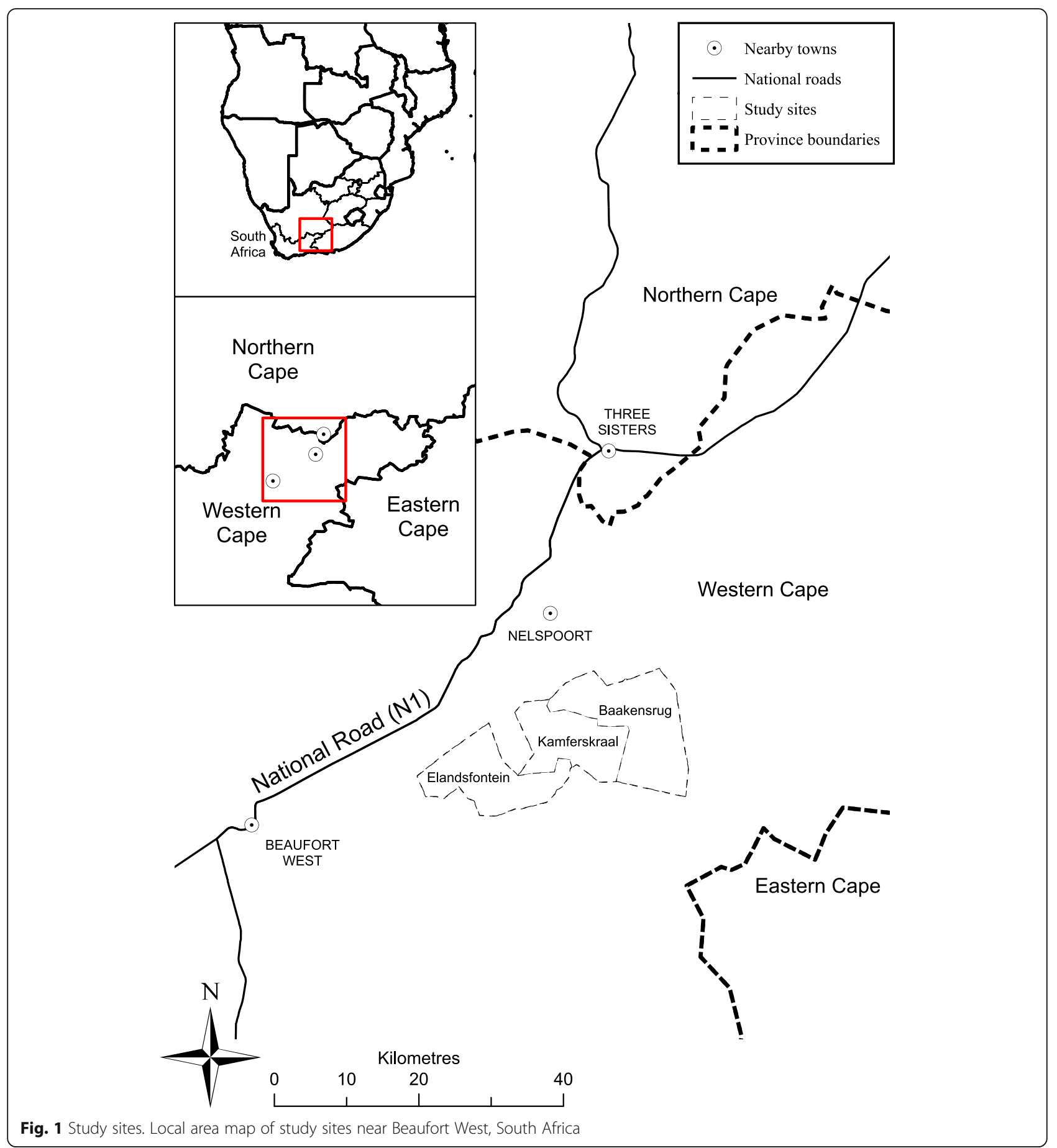

0.98.1091 [67]. Data were discarded based on values for extreme horizontal dilution of precision (HDOP) values, incorrect time zones, incomplete or dubious transmitter data (e.g. negative activity), impossible and improbable movement distances, and z-coordinate error.

\section{Habitat extraction and proximity}

A 2014 South Africa land cover layer was downloaded from GEOTERRAIMAGE (Pretoria, South Africa). The land cover layer is a raster that categorises land area as a habitat; for example, grassland, low shrubland, or cultivated commercial fields. ArcGIS was used to crop raster to local area. Habitats were extracted from the raster layer to each GPS location, with extracted results saved as an Excel file. The land cover raster layer was converted to place a point for each $3 \mathrm{~m} \times 3 \mathrm{~m}$ pixel.

In addition, two other important layers were also used; inland water areas, and manmade water source points; 
taken from a 1:50,000 topographical map of South Africa. These two layers represent potentially important water features that may not be recognised by the land cover layer, as the feature is within a forested area (and so would be classified as the top layer) or is too small to be recognised in the South Africa land cover layer (manmade wells and feeding or drinking stations for livestock). We calculated an individual's Euclidean distance to water resources (inland water areas and manmade water source points) to create an additional predictor variable for generalized linear mixed models (GLMMs).

For purpose of identifying associations with habitats that might supply more food resources, we grouped other habitat categories (dense bush, open bush, wetland, grassland, cultivated commercial fields) based on expectations compared to low shrubland and non-vegetated habitats (Table 1). We grouped the cultivated commercial field categories, which were previously separated into high, medium or low layers. Other habitat types were excluded, due to no nearby tortoise location data. We used the proximity function to also calculate distances to a) water resources, b) increased food resources, and 3) cultivation areas.

\section{Statistics}

Prior to calculating distances between tortoise locations, transmitter fix error was quantified. We used Euclidean distances between fix locations and known transmitter locations in Pietermaritzburg, South Africa, prior to transmitter deployment. Test data had a mean $( \pm$ SE) fix error of $17.01 \pm 0.59 \mathrm{~m}$ (range: 1.78 to $134.78 \mathrm{~m}$ ).

Distances between transmitter locations and subsequent statistical analyses were carried out in R [65] using
RStudio [67]. Bihourly movement was calculated using 'adehabitatLT, 'adehabitatMA', 'ade4' and 'sp' [66]. We assumed each movement was Euclidean distance between successive locations [68]. We assumed each location fix was affected by a fix error. We ranked calculated distance for each movement and assumed larger distances were more likely to be due to larger fix errors. Therefore, we corrected each calculated distance by deducting inverse $\log$ of the quantile for the known error fixes (Equation 1), where $d_{\text {rank }}$ is the $d_{\text {th }}$ percentile from log transformed known error distribution, $\mathrm{d}_{\text {est }}$ is estimated distance between points, and $d_{\text {corr }}$ is corrected distance.

$$
d_{\text {corr }}=d_{\text {est }}-10^{\log \left(d_{\text {rank }}\right)}
$$

In addition to the above, data was also screened based on z-coordinate error [69]. Internal transmitter altitude estimates were compared with approximate heights in digital elevation models (DEMs) - freely available from 'raster' version 2.5-2 package [70] - and discarded when $\mathrm{z}$-coordinate error exceeded $100 \mathrm{~m}$. Fixes were also discarded if time record was not approximate to predefined settings (e.g. > $120 \mathrm{~s}$ after intended fix), which would indicate error in transmitter functionality or inaccuracy based on receiving satellite data.

Cumulative distances were calculated for daily and monthly periods for all but one individual: LPD006 was excluded from analyses due to death and reduced data. Bihourly and daily movement distances were tested for normality using a 'quantile-quantile' plot using 'stats' version 3.1.2 package in $R$ [65]. As these data were heavily right-skewed, log transformations of both bihourly and daily datasets were carried out prior to analyses. As

Table 1 Habitat and resource groupings used in the current study

\begin{tabular}{llll}
\hline Land cover layer classification & Updated classification & Additional layers & Resource categories \\
\hline Water seasonal & Water seasonal & - & Water \\
Water permanent & Water permanent & - & Water \\
Wetlands & Wetlands & - & Food \\
Thicket/Dense bush & Dense bush & - & Food \\
Woodlan/Open bush & Open bush & - & Food \\
Grassland & Grassland & - & Food \\
Low shrubland & Low shrubland & - & None \\
Cultivated comm fields (high) & Cultivated commercial fields & - & Food \\
Cultivated comm fields (med) & Cultivated commercial fields & - & Food \\
Cultivated comm fields (low) & Cultivated commercial fields & - & Food \\
Bare none vegetated & Non-vegetated & Manmade water source points & None \\
- & - & Inland water areas & Water \\
\hline
\end{tabular}

(Habitat classifications were from 2014 South Africa land cover layer, GEOTERRAIMAGE (Pretoria, South Africa). Additional layers include manmade water source points and inland water areas from a 1:50,000 topographical map of South Africa. Resource categories are based on expected access to increased food resources and water.) 
tortoise movement can be strongly affected by environmental conditions [22], we compared the study year to long-term data for the region. We used Welch two sample t-tests to compare monthly mean temperature and total rainfall data to previous years.

GLMMs were used to create and test models to compare effect of predictor variables on bihourly and daily movement. Predictor variables used were a mix of individual, environmental and weather variables; habitat, month, sex, time of day, distance from water source, mean temperature, and total rainfall. Tortoise ID was set as the random variable to account for pseudoreplication. To ensure data were standardised, we used the standardize function in 'arm' version 1.8-6 package in R [71]. For daily models, habitat type for each datapoint was determined as the most common habitat type used by individual for each day. Time of day was not included in daily analysis, as hour-sensitive data were combined for each day. For the continuous predictor variables in daily models we took the mean result for all locations during that day. Aside from temperature, continuous predictor variables used in bihourly models did not use mean results. All possible combination models were tested using the 'glmer' function within 'Ime4' version 1.1-10 package [72] and 'dredge' function using 'MuMIn' version 1.15.6 package [73].

Top candidate models $\left(\Delta \mathrm{AIC}_{\mathrm{c}}<2\right)$ were selected for bihourly and daily GLMMs, with models ranked based on values for $\mathrm{AIC}_{\mathrm{c}}$; Akaike's Information Criterion, adjusted for small sample size [74]. As both GLMMs provided more than one top model, model averaging was used to identify important predictor variables and model coefficients based on those variables. All mean movement results are reported with standard error $( \pm$ SE). Interaction effects for important predictor variables in both models were tested using analysis of deviance in 'phia' version $0.2-1$ package [75]. For bihourly models, we tested effect of month and time on other variables, whilst month and habitat were tested for daily models. Predictor variables not identified as important were excluded from post-hoc analyses.

\section{Results}

\section{Movement summary}

As mentioned, relocation data were collected from 10 telemetry transmitters on adult leopard tortoises from November 2014 to December 2015. LPD048 was tracked for only 283 days, as the transmitter was redeployed following death of LPD006. All other individuals were tracked for a minimum of 359 days. In total, 42,467 data points were collected (Table 2). The data screening process removed 5,413 data points: a mean $( \pm$ SE) of $541.3( \pm 77.20)$ per individual. The final bihourly dataset consisted of 37,054 data points.
Table 2 Biological information for each telemetered individual leopard tortoise, along with the number of geolocation fixes used in final analyses for each

\begin{tabular}{lllll}
\hline Individual & Farm & Sex & Body mass (g) & Screened fixes \\
\hline LPD001 & Baakensrug & Female & 11,685 & 4017 \\
LPD002 & Baakensrug & Female & 11,580 & 3587 \\
LPD004 & Baakensrug & Male & 7,425 & 4122 \\
LPD010 & Kamferskraal & Female & 26,167 & 4159 \\
LPD011 & Kamferskraal & Female & 18,400 & 3647 \\
LPD013 & Kamferskraal & Male & 12,560 & 3790 \\
LPD015 & Elandsfontein & Male & 15,125 & 3941 \\
LPD016 & Elandsfontein & Male & 14,870 & 3330 \\
LPD017 & Elandsfontein & Female & 16,638 & 3884 \\
LPD048* & Baakensrug & Male & 9,275 & 2577 \\
\hline
\end{tabular}

*Telemetered individual LPD006 was found dead through course of study. The GPS unit was recovered and reattached to a new individual (LPD048). Data from the dead tortoise were excluded from the analyses

Bihourly and daily movement of leopard tortoises were calculated for each individual throughout course of the study period. Overall mean distance moved by leopard tortoises was $257.7( \pm 3.64) \mathrm{m}$ per day (range: 1.79 to $2611.24 \mathrm{~m})$. Males $(291.6 \pm 6.00 \mathrm{~m})$ appeared to move further than females (225.9 \pm $4.11 \mathrm{~m})$, although largest daily distance moved was by a female $(2611.24 \mathrm{~m})$. The largest daily distance by a male tortoise was $2477.31 \mathrm{~m}$. Movement varied seasonally, with spring months of September $(302.0 \pm 14.68 \mathrm{~m})$, October $(471.7 \pm 20.57 \mathrm{~m})$, and November (295.6 \pm $14.66 \mathrm{~m})$ showing largest daily movement distances (Fig. 2, Table 3). Mean daily movement was consistently above $150 \mathrm{~m}$ per day throughout much of the year, but winter months showed the shortest movement distances; June $(162.1 \pm 4.84 \mathrm{~m})$, July $(157.6 \pm 4.09 \mathrm{~m})$, and August $(191.1 \pm 6.46 \mathrm{~m})$.

\section{Habitat type associations}

Habitat extractions showed variability between individual leopard tortoises. Whilst $85.1 \%$ of all data points were within habitat classified as 'low shrubland', two individuals were found in low shrubland habitat less than $50 \%$ of the time. In each, dense bush was an important habitat type, with over $30 \%$ of data points. Use of wetlands $(0.05 \%)$, grassland $(1.1 \%)$, and non-vegetated (2.1\%) habitats were used infrequently, although amount of land covered by each of these was much lower than low shrubland. There were changes to habitat use throughout the year (Table 4), in particular during winter months (June to August), where individuals appeared to stay in low shrubland areas.

The above is also reflected by associations leopard tortoises had with features. Only one telemetered individual (LPD011) approached within $250 \mathrm{~m}$ of cultivated 


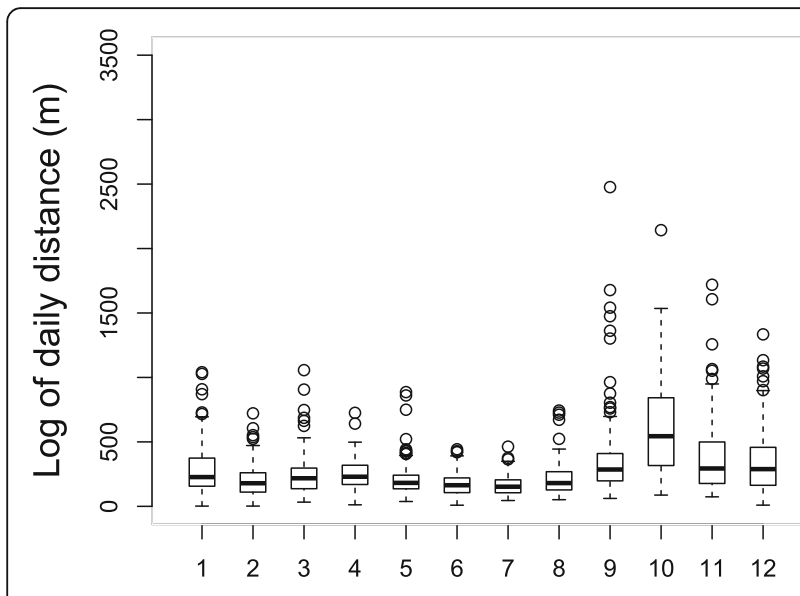

a) Male - Month

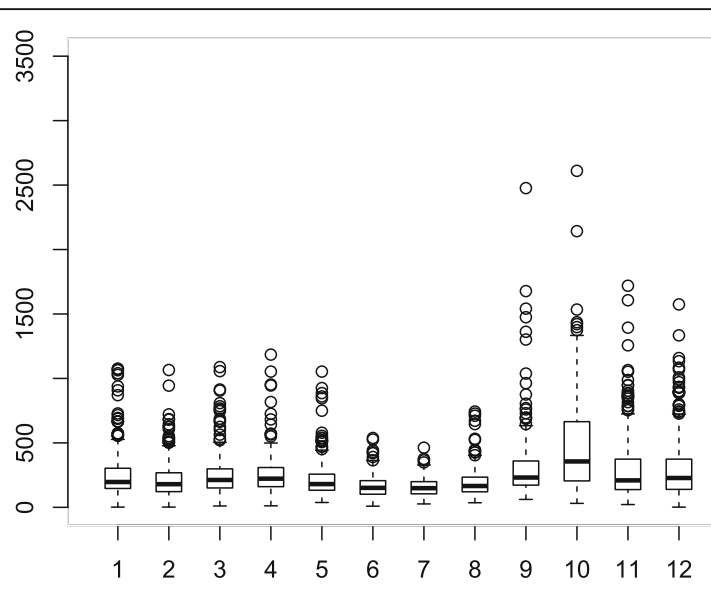

b) Female - Month

Fig. 2 Sex variation in daily movement. Daily movement in adult a) male $(n=5)$, and $\mathbf{b})$ female $(n=5)$ leopard tortoises for each month of the study period, near Beaufort West, South Africa. (Numbers on the $\mathrm{x}$-axis correspond to months; e.g. 1 = January, 2 = February, 3 = March, etc)

commercial fields. Majority of data points showed no association with water resources, with $77.2 \%$ of data points away $(>250 \mathrm{~m})$ from these areas. Only $47.2 \%$ of data points were within close proximities to habitats listed as providing increased food resources.

\section{Weather comparison to previous years}

Mean monthly temperature during study period (18.2 $\pm 1.36{ }^{\circ} \mathrm{C}$ ) did not significantly deviate from longterm (from September 1993) monthly temperature $\left(17.9 \pm 0.26{ }^{\circ} \mathrm{C}\right.$ ) (Welch two sample $t$-test, $\mathrm{t}_{(12)}=-0.2096$, $P=0.838)$. Similarly, mean monthly rainfall was low $(14.2 \pm 2.65 \mathrm{~mm})$ when compared with other years $(21.5 \pm 1.43 \mathrm{~mm})$, though no significant difference was found $\left(\mathrm{t}_{(12)}=0.4005, P=0.696\right)$.

\section{Bihourly movement}

Bihourly movement behaviour of leopard tortoises showed a bimodal pattern during spring and summer, with highest movement during late morning and midafternoon. This bimodal pattern was more pronounced in summer (Fig. 3), whereby movement was highest around 10:00 and 18:00 and generally decreased at 14:00. A unimodal pattern is observed during autumn and winter. Movement was identified during night-time hours during all months of the year, though this was decreased in winter.

A total of 128 candidate models were tested to predict bihourly movement of leopard tortoises. We identified two top candidate models $\left(\Delta \mathrm{AIC}_{\mathrm{c}}<2\right)$ (Table 5). Model averaging highlighted five important predictor variables,

Table 3 Sex differences in daily movement of leopard tortoises for each month, along with weather conditions

\begin{tabular}{|c|c|c|c|c|c|}
\hline \multirow[t]{2}{*}{ Month } & \multicolumn{3}{|c|}{ Daily distance moved (mean \pm SE) in metres } & \multirow[t]{2}{*}{ Average temperature $\left({ }^{\circ} \mathrm{C}\right)$} & \multirow{2}{*}{$\begin{array}{l}\text { Total } \\
\text { Rainfall } \\
(\mathrm{mm})\end{array}$} \\
\hline & Total & Male & Female & & \\
\hline January & $256.0 \pm 11.29$ & $292.2 \pm 18.99$ & $227.5 \pm 13.16$ & 25.3 & 7.0 \\
\hline February & $218.0 \pm 9.71$ & $200.9 \pm 12.97$ & $232.3 \pm 14.08$ & 22.7 & 13.2 \\
\hline March & $248.2 \pm 9.10$ & $240.7 \pm 12.40$ & $255.6 \pm 13.31$ & 22.2 & 28.4 \\
\hline April & $256.5 \pm 9.59$ & $291.7 \pm 6.00$ & $260.1 \pm 16.05$ & 16.8 & 0.0 \\
\hline May & $218.2 \pm 8.15$ & $208.5 \pm 10.14$ & $227.8 \pm 12.74$ & 16.6 & 1.2 \\
\hline June & $162.1 \pm 4.84$ & $175.4 \pm 7.08$ & $148.9 \pm 6.44$ & 11.5 & 15.2 \\
\hline July & $157.6 \pm 4.09$ & $165.1 \pm 6.23$ & $150.0 \pm 5.24$ & 10.6 & 20.4 \\
\hline August & $191.1 \pm 6.46$ & $212.2 \pm 10.30$ & $170.5 \pm 7.54$ & 14.7 & 25.0 \\
\hline September & $302.0 \pm 14.68$ & $371.1 \pm 26.15$ & $233.0 \pm 10.80$ & 15.1 & 8.8 \\
\hline October & $471.7 \pm 20.57$ & $624.1 \pm 29.74$ & $319.3 \pm 22.64$ & 20.7 & 17.8 \\
\hline November & $296.6 \pm 14.66$ & $390.1 \pm 24.41$ & $207.2 \pm 13.21$ & 19.9 & 10.2 \\
\hline December & $306.7 \pm 14.31$ & $349.8 \pm 23.02$ & $275.4 \pm 17.89$ & 23.3 & 23.8 \\
\hline
\end{tabular}


Table 4 Leopard tortoise habitat types used throughout the year

\begin{tabular}{llllllllllllll}
\hline Habitat type & Jan & Feb & Mar & Apr & May & Jun & Jul & Aug & Sep & Oct & Nov & Dec & Mean $( \pm$ SE) \\
\hline Low shrubland & 2351 & 1999 & 2312 & 2241 & 2900 & 3019 & 3156 & 2963 & 2672 & 2634 & 2187 & 2659 & $2591.08 \pm 107.34$ \\
Non-vegetated & 158 & 140 & 86 & 8 & 34 & 18 & 15 & 50 & 80 & 42 & 25 & 129 & $65.42 \pm 15.15$ \\
Dense bush & 203 & 340 & 453 & 137 & 195 & 7 & 14 & 194 & 264 & 321 & 788 & 144 & $255.00 \pm 60.98$ \\
Open bush & 120 & 4 & 102 & 191 & 67 & 41 & 20 & 19 & 115 & 174 & 121 & 31 & $83.75 \pm 18.08$ \\
Grassland & 2 & 1 & 36 & 1 & 25 & 0 & 0 & 0 & 64 & 55 & 41 & 163 & $32.33 \pm 13.69$ \\
Wetlands & 3 & 6 & 5 & 0 & 0 & 0 & 0 & 0 & 0 & 2 & 1 & 0 & $1.42 \pm 0.62$ \\
Cultivated commercial fields & 0 & 31 & 127 & 3 & 0 & 0 & 0 & 0 & 0 & 40 & 0 & 0 & $16.75 \pm 10.78$ \\
Water permanent & 0 & 0 & 6 & 0 & 0 & 0 & 0 & 0 & 0 & 0 & 0 & 0 & $0.50 \pm 0.50$ \\
Total & 2837 & 2521 & 3127 & 2581 & 3221 & 3085 & 3205 & 3226 & 3195 & 3268 & 3163 & 3126 \\
\hline
\end{tabular}

(Numbers represent the number of data points for each habitat type for each month of the year.)

based on relative importance (RI); month, time of day, distance from water source, mean temperature (all RI = 1.00), and total rainfall $(\mathrm{RI}=0.44)$ (Table 6$)$. Habitat type and sex were not statistically significant predictor variables in either top candidate model.

Results showed a positive relationship between movement distance of leopard tortoises and mean temperature, and rainfall (Fig. 4). There was a negative relationship for movement with distance from water source. Month as a predictor variable also showed that movement was expected to be highest in spring (September to November), with lowest movement predicted in winter (June to August).
A significant interactive effect was found for month and distance from water, indicating that effect of distance from water on bihourly movement is dependent on time of year (Table 7). No other interaction effects were significant.

\section{Daily movement}

When aggregating daily habitat type, only one location recorded wetlands as a habitat. This record was excluded from the dataset prior to GLMM analysis. A total of 64 candidate models were tested to predict daily movement distances. We identified two top candidate

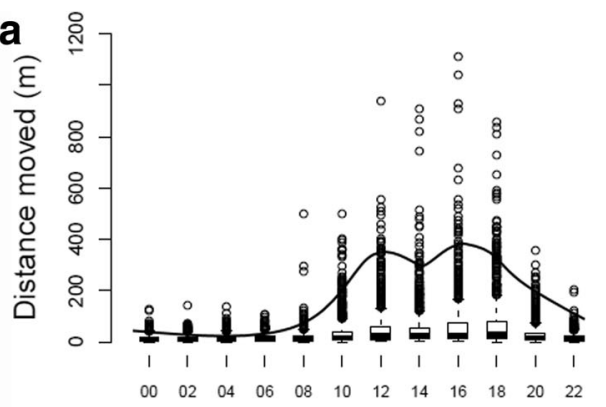

Time of day

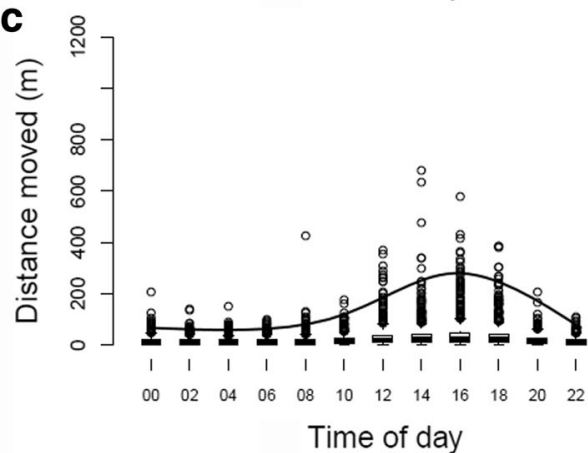

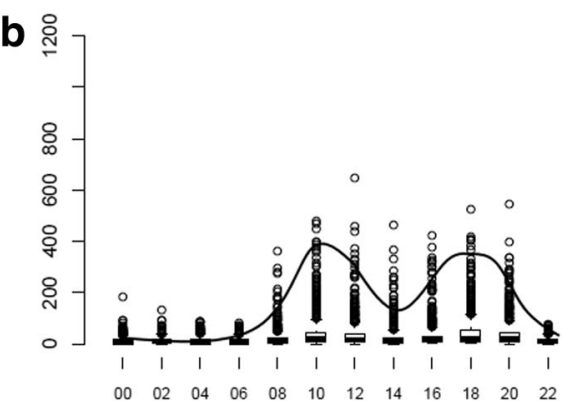

Time of day
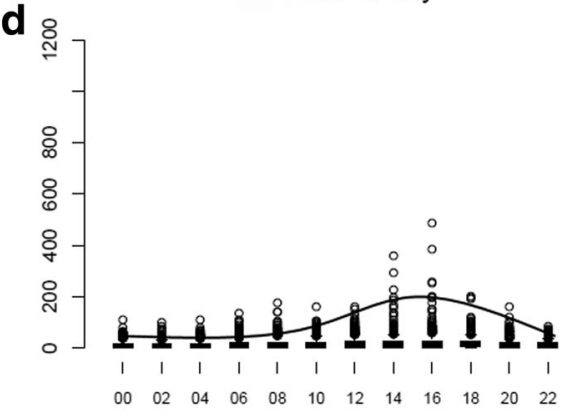

Time of day

Fig. 3 Seasonal variation in daily movement. Bihourly movement of adult leopard tortoises ( $n=10)$ throughout day and night in a) spring (September to November), b) summer (December to February), c) autumn (March to May), and d) winter (June to August), near Beaufort West, South Africa. Lines indicate general activity patterns for that season 
Table 5 Bihourly movement top models in the current study showing results from top GLMMs comparing model fitness for bihourly movement for leopard tortoises

\begin{tabular}{|c|c|c|c|c|c|}
\hline Model & df & log.like & $\mathrm{AlC}_{\mathrm{c}}$ & $\Delta \mathrm{AIC}_{\mathrm{c}}$ & $w_{i}$ \\
\hline month + time + water + temp & 27 & -23481.89 & 47017.82 & 0 & 0.521 \\
\hline month + time + water + rain + temp & 28 & -23481.13 & 47018.30 & 0.48 & 0.409 \\
\hline month + sex + time + water + temp & 28 & -23483.52 & 47023.10 & 5.28 & 0.037 \\
\hline month + sex + time + water + rain + temp & 29 & -23482.77 & 47023.58 & 5.76 & 0.029 \\
\hline habitat + month + time + water + temp & 34 & -23480.30 & 47028.67 & 10.86 & 0.002 \\
\hline habitat + month + time + water + rain + temp & 35 & -23479.79 & 47029.65 & 11.83 & 0.001 \\
\hline
\end{tabular}

Notes: $d f$ degrees of freedom, log.like $=\log$ likelihood, $\Delta \mathrm{AIC}_{\mathrm{c}}=$ deviation for $\mathrm{AIC}_{\mathrm{c}}$ compared with top model, $w_{i}=\mathrm{AIC}_{\mathrm{c}}$ weight

(Predictor variables included habitat type, month, sex, time of day, distance from water source, mean temperature, and total rainfall. Rows shown in bold indicate top models $(\triangle \mathrm{AIC}<2)$. Rainfall and temperature measurements were from the two hour period prior to positional fix, using data supplied by South African

Weather Service (Pretoria, South Africa) for Beaufort West area, South Africa)

models $\left(\Delta \mathrm{AIC}_{\mathrm{c}}<2\right)($ Table 8$)$. The important predictor variables were habitat type, month, distance from water source (all RI $=1.00)$, and mean temperature $(\mathrm{RI}=0.70)$ (Table 9).

Temperature (positive relationships), distance from water source (negative relationship), and month variables presented similar results when compared with bihourly models (Fig. 5). Effect of habitat type on predicted movement was variable. Highest movement was predicted at low shrubland and cultivated commercial fields, whilst non-vegetated land predicted lowest movement. Sex and rainfall were not statistically significant predictor variables in either top candidate model predicting daily movement.

Significant combination effects for daily movement were shown for month, habitat type, and distance from water, indicating that effect of these variables on daily movement is affected by each other (Table 10). Temperature did not show any interactive effects with other important predictor variables.

\section{Discussion}

Movement and activity in tortoises is influenced by life history, resource availability, thermoregulatory necessities, habitat fragmentation, and reproductive requirements [76]. Although daily movement in leopard tortoises is generally affected by season, daily movement is generally short. Previous estimations of daily movement of leopard tortoises (usually $<100 \mathrm{~m}$ ) [31, 33, 43] were much lower than present study $(256.97 \pm 3.56 \mathrm{~m}$ per day). Sporadic large movements by individuals (up to $8 \mathrm{~km}$ ) have been recorded [33], although most other studies show maximum long distance movement of leopard tortoises is approximately $4 \mathrm{~km}[26,31]$. Movement in more arid environments of the Nama-Karoo [33] was higher than in Eastern Cape, South Africa [43], Swaziland [31], and Zimbabwe [42]. Variation in movement distances of the above studies has been attributed to seasonal temperature, availability of food resources, rainfall, differences in mean body mass, and need to ingest key isolated resources (e.g. sodium) [31, 33, 42]. In our study GLMMs identified multiple important climatic, environmental, and individual predictor variables on two temporal scales (bihourly and daily). Three variables (mean temperature, distance from water resource, and month) were important predictor variables in top candidate models for both GLMMs. Three additional predictor variables were also important: rainfall and time of day (bihourly movement), and habitat type (daily movement).

Male leopard tortoises moved further than females overall, and in seven individual months, including each month in spring (September to November), which is when breeding activity (reproduction and egg-laying) in leopard tortoises is typically high [46, 47]. However, sexual differences in movement were not highlighted in either GLMM. This is contradictory to the majority of published tortoise movement ecology studies which show that male movement is significantly higher than females [22, 32, 36, 37]. Peak movement in leopard tortoises of both sexes occurred in spring (September to November). There was a female lag behind males for peak movement: male movement began to increase in September, whilst female movement increased in October. October was the peak month of movement for both sexes. This supports previous research on leopard tortoises [58]. These peaks could be related to individual reproductive status. Mate-searching in tortoises, conducted primarily by males, generally occurs in spring when resource availability and climatic conditions are suitable [58]. Female movement may increase following fertilisation in mid-spring, as search for suitable egg-laying habitat begins [36]. As leopard tortoises can occur at very low densities (e.g. 0.017 tortoises per ha) in some parts of the Karoo [25], it can be expected that males make much larger movements to find mates compared with other species and other regions. This is supported by research on Gopherus tortoises, where males made larger daily spring movements (up to $500 \mathrm{~m}$ ) in areas of lower burrow (and therefore population) density in search of mates [37]. Associated with reproduction is an increase in energy costs: especially for females with 
Table 6 Statistically significant predictor variables for bihourly movement in leopard tortoises

\begin{tabular}{|c|c|c|c|c|c|c|}
\hline \multirow[b]{3}{*}{ (Intercept) } & \multirow[t]{2}{*}{$\beta$} & \multirow[t]{2}{*}{ SE } & \multirow[t]{2}{*}{$z$} & \multicolumn{2}{|c|}{ Confidence intervals } & \multirow[t]{2}{*}{$\mathrm{RI}$} \\
\hline & & & & $2.5 \%$ & $97.5 \%$ & \\
\hline & 1.009 & 0.037 & 27.26 & 0.94 & 1.08 & - \\
\hline Month $^{a}$ & & & & & & 1.00 \\
\hline January & -0.010 & 0.013 & 0.72 & -0.04 & 0.02 & \\
\hline February & -0.047 & 0.013 & 3.47 & -0.07 & -0.02 & \\
\hline March & -0.018 & 0.013 & 1.46 & -0.04 & 0.00 & \\
\hline May & -0.025 & 0.012 & 2.02 & -0.05 & -0.00 & \\
\hline June & -0.086 & 0.013 & 6.76 & -0.11 & -0.06 & \\
\hline July & -0.081 & 0.013 & 6.34 & -0.11 & -0.06 & \\
\hline August & -0.057 & 0.037 & 4.66 & -0.08 & -0.03 & \\
\hline September & 0.044 & 0.012 & 3.55 & 0.02 & 0.07 & \\
\hline October & 0.0114 & 0.012 & 9.25 & 0.09 & 0.14 & \\
\hline November & 0.010 & 0.012 & 0.79 & -0.01 & 0.03 & \\
\hline December & -0.011 & 0.013 & 0.87 & -0.04 & 0.01 & \\
\hline Time of day ${ }^{b}$ & & & & & & 1.00 \\
\hline $2 \mathrm{am}$ & -0.008 & 0.012 & 0.68 & -0.03 & 0.02 & \\
\hline $4 \mathrm{am}$ & 0.015 & 0.012 & 1.27 & -0.01 & 0.04 & \\
\hline $6 \mathrm{am}$ & 0.021 & 0.012 & 1.77 & -0.00 & 0.04 & \\
\hline $8 \mathrm{am}$ & 0.058 & 0.012 & 4.86 & 0.03 & 0.08 & \\
\hline $10 \mathrm{am}$ & 0.176 & 0.012 & 14.90 & 0.15 & 0.20 & \\
\hline $12 \mathrm{pm}$ & 0.228 & 0.012 & 18.90 & 0.20 & 0.25 & \\
\hline $2 \mathrm{pm}$ & 0.190 & 0.012 & 15.21 & 0.17 & 0.21 & \\
\hline $4 \mathrm{pm}$ & 0.248 & 0.013 & 19.41 & 0.22 & 0.27 & \\
\hline $6 \mathrm{pm}$ & 0.281 & 0.012 & 22.53 & 0.26 & 0.31 & \\
\hline $8 \mathrm{pm}$ & 0.143 & 0.012 & 11.93 & 0.12 & 0.17 & \\
\hline $10 \mathrm{pm}$ & 0.018 & 0.012 & 1.52 & -0.01 & 0.04 & \\
\hline Distance from water & -0.101 & 0.008 & 11.86 & -0.12 & -0.08 & 1.00 \\
\hline Rainfall & 0.016 & 0.005 & 0.82 & 0.01 & 0.03 & 0.44 \\
\hline Temperature & 0.072 & 0.008 & 8.48 & 0.06 & 0.09 & 1.00 \\
\hline
\end{tabular}

Notes: ${ }^{\mathrm{a}}=$ April used as reference for month variable. ${ }^{\mathrm{b}}=00$ am used as reference for time of day variable

(Unconditional parameter estimates, standard error, confidence intervals and relative importance (RI) of tested predictor variables for bihourly displacement distances, using two top candidate models $\left(\Delta \mathrm{AlC}_{\mathrm{c}}<2\right)$. Predictor variables shown include month, time of day, distance from water source, total rainfall, and mean temperature)

regards to producing eggs $[32,35]$. Tortoises of both sexes generally increase activity, not only to search for mates and egg-laying habitat, but also for increased demand for food intake and, in case of females, other important resources [35, 37]. No specific instances of reproductive behaviour was observed, though one male (LPD013) was observed alongside several non-telemetered females at a watering point during December 2015.

Habitat type was found to be an important predictor variable for predicting daily leopard tortoise movement. Daily movement was shown to be highest in low shrubland habitat, the most-used habitat type. Cultivated commercial fields also predicted high movement distances, although only one individual used this habitat. We classified multiple habitat types as providing an expected higher supply of food resources, compared with low shrubland and non-vegetated habitats. However, only two individuals remained in these areas throughout majority of the study. The results showed that non-vegetated habitat type was predicted to have lowest movements by daily models, which supports previous research that shows that activity is decreased when resources are low [22]. Our classification for higher food resources was based on expected resources from a land cover layer. However, no surveys were conducted for these habitat types and diet in leopard tortoises is extremely adaptable. Diet-switching behaviour has been identified in leopard tortoises whereby they feed on different plants through year, depending on resource availability [18]. In addition, they will feed on a wide variety of foods, including grasses, forbs, fruits, and succulents [18]. Succulents are even avoided by livestock [18], and are sometimes present in overgrazed areas, such as non-vegetated habitat (unpublished observations). Therefore, smaller movements by individuals in non-vegetated habitat may be due to a higher food searching efficiency by leopard tortoises.

Distance from known water sources was an important predictor in both GLMMs. Contrary to our predictions, movement decreased as individuals moved away from water resources. As forbs (74.5\%) and succulents (51.0\%) generally represent a large percentage of their diet [77], it is likely that high water content of these plants could supplement water intake for individuals for much of the year, especially in such a water scarce habitat [31]. In addition, leopard tortoises are able to adapt digestive parameters (food intake, water loss and urine osmolality) in response to diet to maintain body mass and water balance [20]. This could make them even more resilient to lack of water associated with arid environments $[22,24]$. Despite their ability to obtain much of their water requirements from food intake and metabolic water, they may need to drink free standing water so supplement their water budget demands and restore osmotic homoeostasis, as high electrolyte contents can cause severe stress and sometimes death [22-24].

It appears leopard tortoise movement increased when individuals were closer to water resources, perhaps because of knowledge of resource localities: animals maintain and continually update a cognitive map [78]. Whereas tortoises further away from permanent water appear to rely on food resources for water intake, if known water sources exist within an animal's home range, individuals may make regular movements to maintain internal water balance, though water balance was not measured. Most telemetered individuals had 


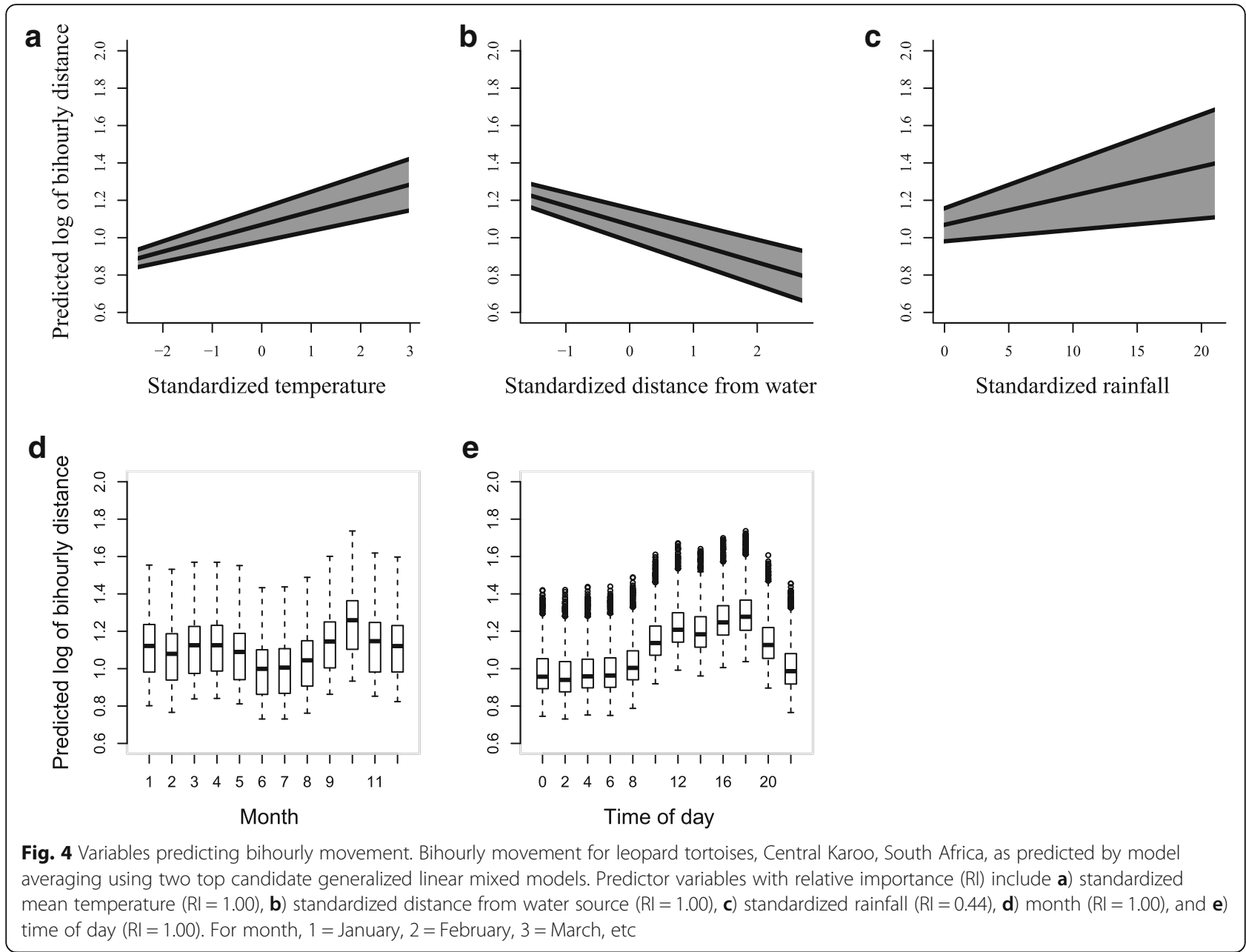

little or no association with known water resources. However, many non-telemetered individuals were frequently observed congregated around manmade watering points and dams (unpublished observations). Such observations have been previously reported, whereby home range of several individuals overlapped at manmade water sources $[25,26]$. This presents a potential issue, considering the upcoming introduction of fracking activities in the Karoo (expected before end of 2017) [8, 9, 79, 80], as contamination of these water sources through increased water salinity and decreased water quality $[10,11]$ could adversely affect a large number of individuals that rely on these permanent water sources. Demand for water in the region already exceeds availability [81, 82], with demand projected to increase by up to $150 \%$ by 2025 [79]. Up to $90 \%$ of water use in South Africa is supplied from surface resources [82], yet infrequent rains in the Karoo rarely reach rivers and cannot supply demand [79]. Whilst it appears that tortoises are able to use food sources for water, it is unknown how fracking will impact these food sources. Further research is required to assess how fracking will affect local human, animal, and plant communities.
The adaptations to water scarce environments are especially important due to unpredictable and infrequent nature of rainfall in the Karoo [49, 50]. Increased tortoise activity is usually found to be associated with rainfall [22, 27-29], with several species having physiological and behavioural adaptations to facilitate drinking rainwater [47, 83]. Our results support these previous findings, with bihourly movement showing a positive relationship with rainfall. This is in contrast to lack of correlation between activity and rainfall found by McMaster and Downs [58] in a similar region. However, one must be cautious when interpreting our results. Whilst no significant difference was found between monthly rainfall during the study year and previous years, rainfall was lower. The mean daily rainfall was $0.44 \mathrm{~mm}$, although over half of rainfall days yielded less than $2 \mathrm{~mm}$ of rain. Rainfall also did not fall in any one particular season; 12 days in spring, 15 days in summer, 6 days in autumn, and 20 days in winter. Tortoises have the ability to use their bladders as water reservoirs [23]. As such, early rains may be more important, and could explain why rainfall was not shown as an important 
Table 7 Analysis of deviance table for predictor variables of bihourly movement

\begin{tabular}{lccc}
\hline Predictor variables & LR & df & Probability \\
\hline Time of day & 25962.2 & 11 & $P>0.001$ \\
Month & 11721.4 & 11 & $P>0.001$ \\
Temperature & 1496.8 & 1 & $P>0.001$ \\
Rainfall & 32.5 & 1 & $P>0.001$ \\
Distance from water & 1703.6 & 1 & $P>0.001$ \\
Month : Temperature & 11.6 & 11 & $P=0.393$ \\
Month : Rainfall & 1.9 & 10 & $P=0.997$ \\
Month : Distance from water & 731.2 & 11 & $P>0.001$ \\
Time of day : Month & 39.4 & 121 & $P=1.000$ \\
Time of day : Temperature & 2.3 & 11 & $P=0.997$ \\
Time of day : Rainfall & 1.2 & 11 & $P=1.000$ \\
Time of day : Distance from water & 10.6 & 11 & $P=0.474$ \\
Time : Month : Temperature & 19.4 & 121 & $P=1.000$ \\
Time : Month : Rainfall & 6.8 & 49 & $P=1.000$ \\
Time : Month : Distance from water & 46.7 & 121 & $P=1.000$ \\
\hline Interactive effect of statistically significant predictor variables for predicting \\
bihourly movement in leopard tortoises. Predictor variables are shown alone, and \\
$\begin{array}{l}\text { with potential interactive variables, along with likelihood ratio (LR) chi-squared } \\
\text { statistic, degrees of freedom (df) and statistical significance (P) values }\end{array}$
\end{tabular}

predictor variable in daily models. Such unpredictability in rainfall increases importance of permanent water resources. Movement studies should ideally be conducted over several seasons, though financial, battery life, and time restrictions vary.

Whilst rainfall is unpredictable, temperature is less so, and has been previously shown as important in dictating movement in tortoise studies [30, 31]. Tortoises are ectothermic, and so activity is directly related to local environmental conditions to support metabolism [58]. As such, tortoises generally move more in spring and summer, with movement decreased in winter [31-34], though patterns are likely more complex and related to specific environments and climatic conditions. Behaviour is also important: tortoises bask in morning sun prior to becoming active during the day [58]. Temperature and
Table 9 Statistically significant predictor variables for daily movement

\begin{tabular}{|c|c|c|c|c|c|c|}
\hline \multirow[b]{3}{*}{ (Intercept) } & \multirow[t]{2}{*}{$\beta$} & \multirow[t]{2}{*}{ SE } & \multirow[t]{2}{*}{$z$} & \multicolumn{2}{|c|}{ Confidence intervals } & \multirow[t]{2}{*}{$\mathrm{Rl}$} \\
\hline & & & & $2.5 \%$ & $97.5 \%$ & \\
\hline & 2.345 & 0.03 & 73.81 & 2.28 & 2.41 & - \\
\hline Habitat type ${ }^{a}$ & & & & & & 1.00 \\
\hline Non-vegetated & -0.291 & 0.04 & 7.75 & -0.36 & -0.22 & \\
\hline Dense bush & -0.138 & 0.02 & 6.81 & -0.18 & -0.10 & \\
\hline Open bush & -0.137 & 0.03 & 4.15 & -0.20 & -0.07 & \\
\hline Grassland & -0.119 & 0.05 & 2.39 & -0.22 & -0.02 & \\
\hline Cultivated fields & -0.132 & 0.06 & 2.05 & -0.26 & -0.01 & \\
\hline Month $^{\mathrm{b}}$ & & & & & & 1.00 \\
\hline January & -0.010 & 0.03 & 0.34 & -0.07 & 0.05 & \\
\hline February & -0.077 & 0.03 & 2.81 & -0.13 & -0.02 & \\
\hline March & 0.005 & 0.03 & 0.20 & -0.05 & 0.06 & \\
\hline May & -0.056 & 0.02 & 2.48 & -0.10 & -0.01 & \\
\hline June & -0.170 & 0.03 & 6.63 & -0.22 & -0.12 & \\
\hline July & -0.172 & 0.03 & 6.55 & -0.22 & -0.12 & \\
\hline August & -0.100 & 0.02 & 4.31 & -0.15 & -0.05 & \\
\hline September & 0.087 & 0.02 & 3.76 & 0.04 & 0.13 & \\
\hline October & 0.207 & 0.02 & 8.57 & 0.16 & 0.25 & \\
\hline November & 0.027 & 0.02 & 1.14 & -0.02 & 0.07 & \\
\hline December & 0.014 & 0.03 & 0.54 & -0.04 & 0.07 & \\
\hline Temperature & 0.048 & 0.01 & 3.20 & 0.02 & 0.08 & 0.70 \\
\hline Distance from water & -0.147 & 0.02 & 8.86 & -0.18 & -0.11 & 1.00 \\
\hline
\end{tabular}

Notes: ${ }^{\mathrm{a}}=$ Low shrubland used as reference for habitat type variable. ${ }^{\mathrm{b}}=$ April used as reference for month variable

Unconditional parameter estimates, standard error, confidence intervals and relative importance (RI) of tested predictor variables for daily movement, using two top candidate models $\left(\Delta \mathrm{AlC}_{\mathrm{c}}<2\right)$. Predictor variables shown include most common habitat type, month, mean temperature, and distance from water source

month were important predictor variables in both GLMMs. Our bihourly data also showed a basic bimodal movement pattern in warmer seasons, when maximum daily temperatures frequently exceeded $30{ }^{\circ} \mathrm{C}$. This bimodal activity pattern (with movement higher during mornings and evenings) is a behavioural adaptation that

Table 8 Daily movement top models

\begin{tabular}{|c|c|c|c|c|c|}
\hline Model & $\mathrm{df}$ & log.like & $\mathrm{AlC}_{\mathrm{c}}$ & $\Delta \mathrm{AIC}_{\mathrm{c}}$ & $w_{i}$ \\
\hline habitat + month + temp + water & 21 & -429.80 & 901.87 & 0 & 0.653 \\
\hline habitat + month + water & 20 & -431.64 & 903.52 & 1.65 & 0.286 \\
\hline habitat + month + sex + temp + water & 22 & -431.70 & 907.69 & 5.83 & 0.035 \\
\hline habitat + month + sex + water & 21 & -433.54 & 909.33 & 7.47 & 0.016 \\
\hline habitat + month + temp + water + rain & 22 & -433.26 & 910.80 & 8.93 & 0.007 \\
\hline habitat + month + water + rain & 21 & -435.33 & 912.93 & 11.06 & 0.003 \\
\hline
\end{tabular}

Notes: $d f$ degrees of freedom, log.like $=\log$ likelihood, $\Delta \mathrm{AIC}_{\mathrm{c}}=$ deviation for $\mathrm{AlC}_{\mathrm{c}}$ compared with top model, $w_{i}=\mathrm{AlC}_{\mathrm{c}}$ weight

Results from top GLMMs comparing model fitness for daily movement for Leopard Tortoises. Predictor variables included habitat type, month, sex, distance from water source, mean temperature, and total rainfall. Rows shown in bold indicate top models $\left(\Delta \mathrm{AlC}_{c}<2\right)$. Rainfall and temperature measurements were provided by South African Weather Service (Pretoria, South Africa) for Beaufort West area, South Africa 


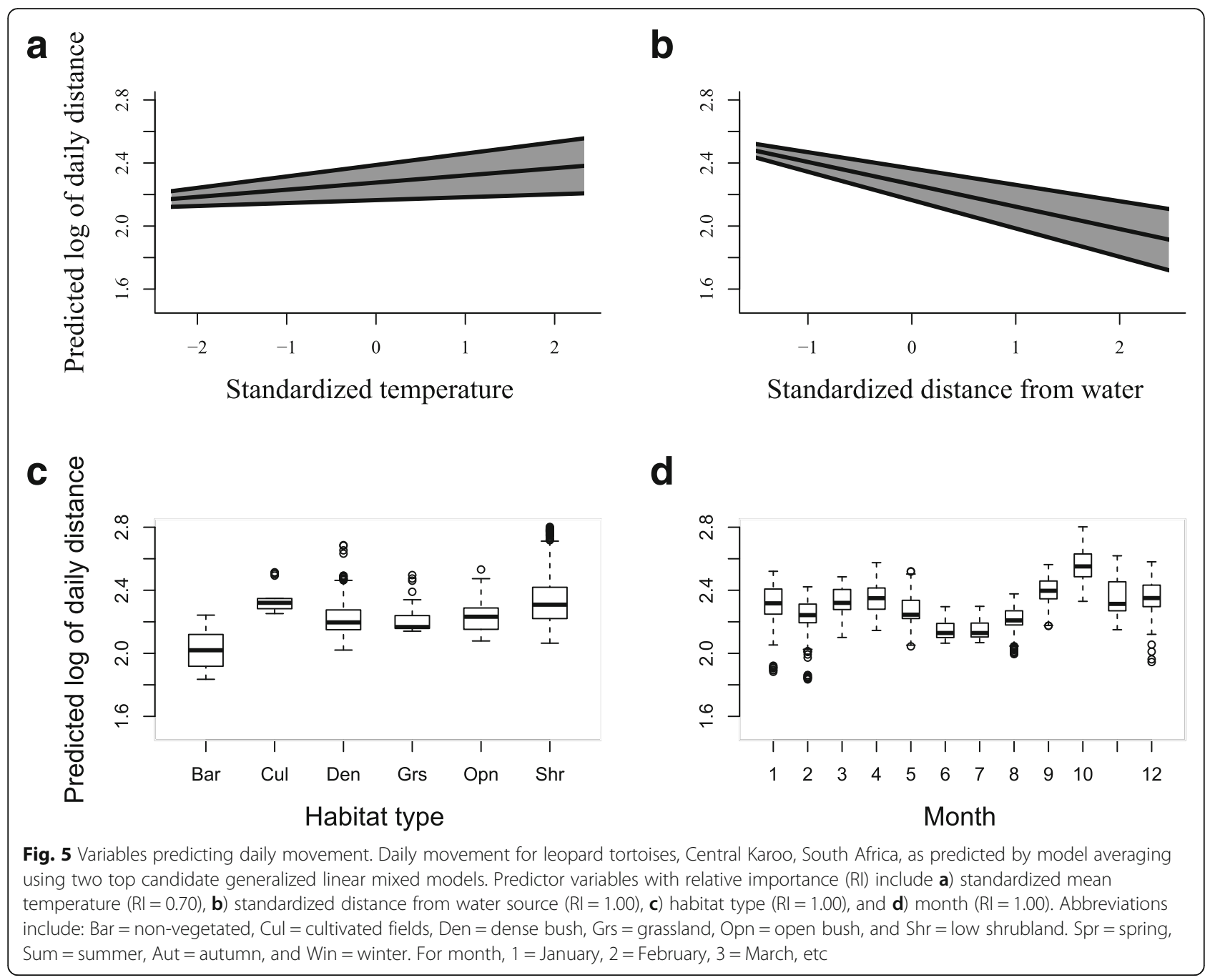

Table 10 Analysis of deviance table for predictor variables of daily movement

\begin{tabular}{lrll}
\hline Predictor variables & LR & df & Probability \\
\hline Month & 8292.0 & 11 & $P<0.001$ \\
Habitat & 3938.9 & 5 & $P<0.001$ \\
Temperature & 98.6 & 1 & $P<0.001$ \\
Distance from water & 810.5 & 1 & $P<0.001$ \\
Month : Habitat & 120.9 & 29 & $P<0.001$ \\
Month : Temperature & 3.0 & 11 & $P<0.001$ \\
Month : Distance from water & 126.4 & 11 & $P<0.001$ \\
Habitat : Temperature & 0.4 & 5 & $P=0.990$ \\
Habitat : Distance from water & 14.7 & 5 & $P=0.012$ \\
Month : Habitat : Temperature & 2.9 & 26 & $P=1.000$ \\
Month : Habitat : Distance from water & 136.3 & 26 & $P<0.001$
\end{tabular}

Interactive effect of statistically significant predictor variables for predicting daily movement in leopard tortoises. Predictor variables are shown alone, and with potential interactive variables, along with likelihood ratio (LR) chi-squared statistic, degrees of freedom (df) and statistical significance $(P)$ values allows individuals to avoid extreme temperatures, which may cause severe stress or death [26, 28, 36, 58, 59]. Indeed, hours of activity restriction due to increased temperatures associated with global warming is believed to be a main predictor for local extinctions of yellow-footed tortoises, Chelonoidis denticulata [84]. Some species (e.g. Testudo spp.) reduce activity in summertime to avoid extreme temperatures [30], whilst others (e.g. Gopherus spp., African spurred tortoise, Centrochelys sulcata) remain in burrows over many weeks [47]. Leopard tortoises are not known to dig burrows, but will use shade of bushes and boulders to shield themselves from sun $[58,85]$.

Due to the close relationship between temperature and activity, leopard tortoise movement is generally restricted in cooler temperatures, such as during winter months and during night-time hours. In more moderate climates, tortoises brumate to avoid cold conditions [22, 30, 34, 47]. However, mean winter (June to August) temperatures in the Karoo are still warm enough to 
facilitate movement: over one third of winter days had maximum temperatures exceeding $20{ }^{\circ} \mathrm{C}$. Mean daily movement of leopard tortoises during winter months exceeded $150 \mathrm{~m}$. Leopard tortoises do not typically brumate $[26,31]$, although isolated records do occur [25]. In contrast to bimodal activity patterns in warmer months, a unimodal activity pattern was observed in autumn and winter, as described previously by McMaster and Downs [58]. McMaster and Downs [58] also noted leopard tortoises are generally inactive during night-time. However, our results show night-time movement does occur, especially in summer and autumn months. Night-time foraging in leopard tortoises has been reported in one individual previously [46]. It is currently unknown what may facilitate night-time movement, although it appears that night-time temperatures are often non-restrictive during these periods. More research is required to ascertain variables enabling this night-time movement. Other potentially important variables, such as environmental illumination, may also affect movement ability during night-time hours when temperatures are non-restrictive.

Information regarding drivers of movement, and periods in which movement is highest, can be used to mitigate against other threats to tortoises. For example, electric fencing is used in much of the Karoo as a means to control predation on livestock by caracal and blackbacked jackal [41]. This electric fencing causes mortalities in a number of mammals, reptiles, and amphibians [56], though fatalities are highest with respect to tortoise species and ground pangolin (Smutsia temmincki) [56]. Leopard tortoises account for most $(>86 \%)$ electric fencing related reptile mortalities $[56,57]$, likely related to their size and spatial ecology. As electric fencing is becoming more affordable in South Africa, tortoise mortalities by electrocutions is increasing. Whilst it has been recommended that raising the electric line to a minimum height of $250 \mathrm{~mm}$ could reduce mortalities [57], strategic planning can also be incorporated into operations by reducing use of electric fencing when and where tortoises are most active: in mornings and evenings, mating season, and nearer to water sources.

\section{Conclusions}

Our results further display the relationship between water as a resource and movement in leopard tortoises. We provide evidence individuals can use either one of two basic movement behaviours in relation to water sources in water scarce environments: either an individual's home range and movement is such that it includes permanent water resources, allowing regular long-distance movements to replenish water storage; or access to these resources are excluded and there is instead a reliance on food resources (such as grasses, forbs, and succulents) as the primary source of water. It is known from previous research that multiple tortoise species are able to tolerate high electrolyte concentrations, though drinking water is a requirement for urination and restoration of water balance. Further research should be carried out on potential impacts of fracking activities, as contamination and increased salination of groundwater may affect ability to restore water balance. Subsequent dehydration could cause severe stress and possible mortality.

In particular our research identified temporal and spatial conditions in which leopard tortoise movement increased. Such information can be used to guide designs, constructions and operations of electric fencing. As leopard tortoise movement is higher in areas closer to water resources, we advise that electric fencing does not occur within close proximities to these areas. We also advise that electric fencing should not operate during spring and summer months, whereby reproductive and general activities are increased. However, our data shows tortoises move throughout the year, and even during night-time hours. Whilst is may not be possible to avoid all mortalities related to electric fencing, we hope that the above suggestions could reduce impacts. Increasing time between shocks, or alternating in electric fence functionality at intervals may also enable shocked individuals to escape should contact occur. We also support previous suggestions whereby the electrified line is raised to a minimum height of $250 \mathrm{~mm}$.

\section{Abbreviations \\ AIC: Akaike's information criterion; GLMM: Generalized linear mixed model; GPS: Global positioning system; GSM: Global system for mobile communications; HDOP: Horizontal dilution of precision; Rl: Relative importance; UHF: Ultra high frequency}

\section{Acknowledgements}

We would like to thank the following people and companies for helping with the study; V. Hugo, Animal Trackem, and Wireless Wildlife, for provision of telemetry equipment, study recommendations, and training for use of telemetry equipment, IDEA WILD for donating key fieldwork equipment, multiple members of the Nelspoort and Beaufort West community, including R. du Toit, D. Jackson, L. Reynolds, and G. Lund, for allowing research on their land and providing field accommodation, C. Elstob, for initiating contact between University of KwaZulu-Natal and the aforementioned landowners, R. Johnson of AIFA, Beaufort West, for flying a base-station device over study sites to search for a missing tortoise, and B. Gijbertsen for providing material, software and training for use with GIS programmes. We would also like to thank M. Pfeiffer, P. Potter, T. van der Meer, P. Singh, K. Pillay, and C. Cormac for hard work as field assistants. We are grateful to the University of KwaZulu-Natal and the National Research Foundation (ZA) for some financial support. We are grateful for the constructive comments of anonymous reviewers.

\section{Funding}

IDEA WILD, Gay Langmuir bursary, the University of KwaZulu-Natal and the National Research Foundation (ZA) provided financial support.

\section{Availability of data and materials}

The datasets generated and/or analysed during the current study are not publicly available due to them being part of a current postgraduate study but are available from the corresponding author on reasonable request. 


\section{Authors' contributions}

$\mathrm{MDH}$ and CTD conceptualised the ms. MDH collected, analysed and interpreted the telemetry data. MDH drafted the ms. All authors revised and approved the final manuscript.

\section{Competing interests}

The authors declare that they have no competing interests.

\section{Consent for publication}

Not applicable.

\section{Ethics approval and consent to participate}

We had ethics approval from the University of KwaZulu-Natal Ethics Committee.

Received: 17 November 2016 Accepted: 22 February 2017

\section{Published online: 20 March 2017}

\section{References}

1. Foley JA, Defries R, Asner GP, Barford C, Bonan G, Carpenter SR, et al. Global consequences of land use. Science. 2005; doi:10.1126/science.1111772

2. 2. Hoffman MT. Changing patterns of rural land use and land cover in South Africa and their implications for land reform. J S Afr Stud. 2014; doi:10.1080/03057070.2014.943525.

3. Kalnay E, Cai M. Impact of urbanization and land-use change on climate. Nature. 2003;423:528-31.

4. Manry D. Distribution, abundance and conservation of the bald ibis Geronticus calvus in southern Africa. Biol Conserv. 1985; doi:10.1016/00063207(85)90076-X.

5. Brooke R, Vernon C. Historical records of the wattled crane Bugeranus carunculatus (Gmelin) in the Cape Province and the Orange Free State, South Africa. Annals of the Cape Provincial Museums (Natural History). 1988;16:363-71.

6. Jackson ADJ. Manna in the desert: A revelation of the Great Karroo. Johannesburg: Christian Literature Depot; 1920.

7. Bažant ZP, Salviato M, Chau VT, Viswanathan H, Zubelewicz A. Why fracking works. J Appl Mech. 2014; doi:10.1115/1.4028192.

8. De Wit MJ. The great shale debate in the Karoo. S Afr J Sci. 2011; doi:10. 4102/sajs.v107i7/8.791

9. Reuters. http://www.reuters.com/article/us-safrica-shalegas-idUSKCNOWA26F

10. Schmidt CW. Estimating wastewater impacts from fracking. Environ $\mathrm{H}$ Persp. 2013; doi:10.1289/ehp.121-a117.

11. Vidic RD, Brantley SL, Vandenbossche JM, Yoxtheimer D, Abad JD. Impact of shale gas development on regional water quality. Science. 2013; doi:10. 1126/science.1235009.

12. Dean WRJ. Where birds are rare or fill the air: The protection of the endemic and the nomadic avifaunas of the Karoo, PhD Thesis. Rondebosch: University of Cape Town; 1995.

13. Branch W, Benn G, Lombard A. The tortoises (Testudinidae) and terrapins (Pelomedusidae) of southern Africa: Their diversity, distribution and conservation. S Afr J Zool. 1995; doi:10.1080/02541858.1995.11448377.

14. Turtle Taxonomy Working Group. [van Dijk, PP, Iverson, JB, Rhodin, AGJ, Shaffer, HB, Bour, R.] Turtles of the world, 7th Edition: Annotated checklist of taxonomy, synonymy, distribution with maps, and conservation status. In: Rhodin, AGJ, Pritchard, PCH, van Dijk, PP, Saumure, RA, Buhlmann, KA, Iverson, JB, et al., editors. Conservation biology of freshwater turtles and tortoises: a compilation project of the IUCN/SSC Tortoise and Freshwater Turtle Specialist Group. Chelonian research monographs; 2014. doi:10.3854/ crm.5.000.checklist.v7.2014.

15. Hofmeyr MD, Boycott RC, Baard EHW. Family Testudinidae. In: Bates MF, Branch WR, Bauer AM, Burger M, Marais J, Alexander GJ, et al., editors. Atlas and Red List of the reptiles of South Africa, Lesotho and Swaziland. Pretoria: South African Biodiversity Institute; 2014. p. 70-85.

16. SANParks. Karoo National Park. http://www.sanparks.co.za/parks/karoo/all. php. Accessed 1 Apr 2015

17. IUCN. IUCN Red List of Threatened Species. International Union for the Conservation of Nature: Published online: http://www.iucnredlist.org/. 2008.

18. Milton SJ. Plants eaten and dispersed by adult leopard tortoises Geochelone pardalis (Reptilia, Chelonii) in the southern Karoo. S Afr J Zool. 1992;27:45-9.

19. Jerozolimski A, Ribeiro MBN, Martins M. Are tortoises important seed dispersers in Amazonian forests? Oecologia. 2009; doi:10.1007/s00442009-1396-8
20. McMaster MK, Downs CT. Digestive parameters and water turnover of the leopard tortoise. Comparative Biochemistry and Physiology, Part A. 2008; doi:10.1016/j.cbpa.2008.06.007.

21. Alexy KJ, Brunjes KJ, Gassett JW, Miller KV. Continuous remote monitoring of gopher tortoise burrow use. Wildlife Soc B. 2003;31:1240-3.

22. Duda JJ, Krzysik AJ, Freilich JE. Effects of drought on desert tortoise movement and activity. J Wildlife Manage. 1999; doi:10.2307/3802836.

23. Nagy KA, Medica PA. Physiological ecology of desert tortoises in southern Nevada. Herpetologica. 1986;42:73-92.

24. Peterson CC. Anhomeostasis: Seasonal water and solute relations in two populations of the desert tortoise (Gopherus agassizii) during chronic drought. Physiol Zool. 1996; doi:10.1086/physzool.69.6.30164263.

25. McMaster MK, Downs CT. Population structure and density of leopard tortoises (Geochelone pardalis) on farmland in the Nama-Karoo. J Herpetol. 2006; doi:10.1670/0022-1511(2006)40[495:Psadol]2.0.Co;2

26. Rall M. Ekologiese waarnemings van'n Bergskilpadpopulasie, Geochelone pardalis Bell, 1828, soos aangeteken in die Soetdoring-Natuurreser-vaat in die Oranje-Vrystaat. Koedoe. 1985; doi:10.4102/koedoe.v28i1.534.

27. Medica PA, Bury RB, Luckenbach RA. Drinking and construction of water catchments by the desert tortoise, Gopherus agassizii, in the Mojave Desert. Herpetologica. 1980:36:301-4.

28. Rose FL, Judd FW. Activity and home range size of the Texas tortoise, Gopherus berlandieri, in south Texas. Herpetologica. 1975;31:448-56.

29. Hailey A, Coulson IM. Temperature and the tropical tortoise Kinixys spekii: Constraints on activity level and body temperature. J Zool. 1996; doi:10. 1111/j.1469-7998.1996.tb05303.x.

30. Díaz-Paniagua C, Keller C, Andreu AC. Annual variation of activity and daily distances moved in adult spur-thighed tortoises, Testudo graeca, in southwestern Spain. Herpetologica. 1995;51:225-33.

31. Monadjem A, McCleery RA, Collier BA. Activity and movement patterns of the tortoise Stigmochelys pardalis in a subtropical savanna. J Herpetol. 2013; doi:10.1670/12-070.

32. Eubanks JO, Michener WK, Guyer C. Patterns of movement and burrow use in a population of gopher tortoises (Gopherus polyphemus). Herpetologica. 2003; doi:10.1655/01-105.1.

33. McMaster MK, Downs CT. Home range and daily movement of leopard tortoises (Stigmochelys pardalis) in the Nama-Karoo, South Africa. J Herpetol. 2009; doi:10.1670/07-078.1

34. Diemer JE. Home range and movements of the tortoise Gopherus polyphemus in northern Florida. J Herpetol. 1992; doi:10.2307/1564857.

35. Henen B. Energy and water balance, diet, and reproduction of female desert tortoises (Gopherus agassizii). Chelonian Conserv Biol. 2002;4:319-29.

36. Van Bloemestein UP. Seasonal movement and activity patterns of the endangered geometric tortoise, Psammobates geometricus, MSc Thesis. Bellville: University of the Western Cape; 2005.

37. Guyer C, Johnson VM, Hermann SM. Effects of population density on patterns of movement and behavior of gopher tortoises (Gopherus polyphemus). Herpetol Monogr. 2012; doi:10.1655/HERPMONOGRAPHS-D-10-00004.1.

38. Henen BT. Seasonal and annual energy budgets of female desert tortoises (Gopherus agassizii). Ecology. 1997;78:283-96.

39. Gibson C, Hamilton J. Feeding ecology and seasonal movements of giant tortoises on Aldabra atoll. Oecologia. 1983; doi:10.1007/BF00378221.

40. Blake S, Yackulic CB, Cabrera F, Tapia W, Gibbs JP, Kummeth F, et al. Vegetation dynamics drive segregation by body size in Galápagos tortoises migrating across altitudinal gradients. J Anim Ecol. 2013; doi:10.1111/1365-2656.12020.

41. Bergman DL, De Waal H, Avenant NL, Bodenchuk M, Marlow MC, Nolte DL. The need to address black-backed jackal and caracal predation in South Africa. In: Wildlife Damage Management Conferences - Proceedings. 2013.

42. Hailey A, Coulson IM. Differential scaling of home-range area to daily movement distance in two African tortoises. Can J Zool. 1996; doi:10.1139/Z96-013.

43. Mason MC, Weatherby CA. Home range of Geochelone pardalis and Chersina angulata: Two sympatric genera in the Eastern Cape, South Africa. African Herp News. 1996;25:10

44. Clobert J, Galliard L, Cote J, Meylan S, Massot M. Informed dispersal, heterogeneity in animal dispersal syndromes and the dynamics of spatially structured populations. Ecol Lett. 2009; doi:10.1111/j.1461-0248.2008.01267.x.

45. Hebblewhite M, Haydon DT. Distinguishing technology from biology: A critical review of the use of GPS telemetry data in ecology. Philos T Royal Soc B. 2010; doi:10.1098/rstb.2010.0087.

46. Grobler J. The leopard tortoise in the Mountain Zebra National Park Koedoe. 1982;25:49-53. 
47. Bonin F, Devaux B, Dupré A. Turtles of the world. London: Bloomsbury Publishing PLC; 2006.

48. Vorster M, Roux P. Veld of the Karoo areas. Proc Ann Cong Grassland Soc S Afr. 1983; doi:10.1080/00725560.1983.9648975.

49. Mucina L, Rutherford MC, Palmer AR, Dold AP. Nama-Karoo biome. In: Mucina L, Rutherford MC, editors. The vegetation of South Africa, Lesotho and Swaziland. Strelitzia 19. Pretoria: South African National Biodiversity Institute; 2006. p. 324-47.

50. Van Rooyen MW. Functional aspects of short-lived plants. In: Dean WRJ, Milton S, editors. The Karoo: Ecological patterns and processes. Cambridge: Cambridge University Press; 1999. p. 107-22.

51. Muller K, O'Connor TG, Henschel JR. Impact of a severe frost event in 2014 on woody vegetation within the Nama-Karoo and semi-arid savanna biomes of South Africa. J Arid Environ. 2016; doi:10.1016/j.jaridenv.2016.06.010.

52. Dean WRJ, Milton SJ. Animal foraging and food. In: Dean WRJ, Milton S, editors. The Karoo: Ecological patterns and processes. Cambridge: Cambridge University Press; 1999. p. 164-76.

53. Milton SJ, Zimmermann HG, Hoffman JH. Alien plant invaders of the Karoo: Attributes, impacts and control. In: Dean WRJ, Milton S, editors. The Karoo: Ecological patterns and processes. Cambridge: Cambridge University Press; 1999. p. 274-87.

54. Hilton-Taylor C. Phytogeography and origins of the Karoo flora. In: Cowling RM, Roux PW, editors. The Karoo biome: a preliminary synthesis: Part 2 - vegetation and history. South African National Scientific Programme Reports. South Africa: Foundation for Research Development; 1987. p. 70-95.

55. Savory A. Holistic resource management: A conceptual framework for ecologically sound economic modelling. Ecological Economics. 1991; doi:10. 1016/0921-8009(91)90031-9.

56. Beck A. Electric fence induced mortality in South Africa, MSc Thesis. Johannesburg: University of the Witwatersrand; 2010.

57. Burger M, Branch WR. Tortoise mortality caused by electrified fences in the Thomas Baines Nature Reserve. S Afr J Wildl Res. 1994;24:32-7.

58. McMaster MK, Downs CT. Seasonal and daily activity patterns of leopard tortoises (Stigmochelys pardalis Bell, 1828) on farmland in the Nama-Karoo, South Africa. Afr Zool. 2013;48:72-83.

59. Hailey A, Coulson IM. Temperature and the tropical tortoise Kinixys spekii: Tests of thermoregulation. J Zool. 1996; doi:10.1111/j.1469-7998.1996. tb05304.x.

60. Boycott RC, Bourquin O. The southern African tortoise book: A guide to southern African tortoises, terrapins and turtles. Pietermaritzburg: Interpak; 2000.

61. Branch B. Tortoises, terrapins \& turtles of Africa. South Africa: Random House Struik; 2012.

62. Gursky S. Effects of radio transmitter weight on a small nocturnal primate. Am J Primatol. 1998; doi:10.1002/(SICI)1098-2345(1998)46:2<145::AID-AJP4>3. $0 . \mathrm{CO} ; 2-\mathrm{W}$

63. Wireless Wildlife. http://www.wireless-wildlife.co.za/. Accessed 7 June 2016

64. South African Weather Service. http://www.weathersa.co.za/. Accessed 9 Nov 2016

65. R Core Development Team. R. A language and environment for statistical computing. Vienna: R Core Development Team. R; 2014.

66. Calenge $\mathrm{C}$. The package adehabitat for the $\mathrm{R}$ software: $\mathrm{A}$ tool for the analysis of space and habitat use by animals. Ecol Model. 2006; doi:10.1016/ j.ecolmodel.2006.03.017.

67. RStudio Team. RStudio: Integrated Development for R. Boston, MA. 2015. http://www.rstudio.com/

68. Conner L, Plowman B. Using Euclidean distances to assess nonrandom habitat use. In: Millspaugh J, Marzluff J, editors. Radio tracking and animal populations. San Diego: Academic; 2001. p. 275-90.

69. Laver PN, Powell RA, Alexander KA. Screening GPS telemetry data for locations having unacceptable error. Ecol Inform. 2015; doi: 10.1016/j.ecoinf. 2015.02.001.

70. Hijmans RJ. raster: Geographic Data Analysis and Modeling. 2015. R package version 2.5-2. http://CRAN.R-project.org/package=raster

71. Gelman A, Su Y-S, Yajima M, Hill J, Pittau MG, Kerman J, et al. arm: Data analysis using regression and multilevel/hierarchical models. 2009. R package, version 9.01. http://CRAN.R-project.org/package=arm

72. Bates D, Mächler M, Bolker B, Walker S. Fitting linear mixed-effects models using Ime4. Journal of Statistical Software. 2015; doi:10.18637/jss.v067.i01.

73. Bartoń K. MuMIn: Multi-model inference. 2016. R package version 1.15.6. http://CRAN.R-project.org/package=MuMIn
74. Hurvich CM, Tsai C-L. Regression and time series model selection in small samples. Biometrika. 1989; doi:10.1093/biomet/76.2.297

75. De Rosario-Martinez H. phia: Post-hoc interaction analysis. 2015. R package version 0.2-1. http://CRAN.R-project.org/package=phia

76. Rozylowicz L, Popescu VD. Habitat selection and movement ecology of eastern Hermann's tortoises in a rural Romanian landscape. Eur J Wildlife Res. 2013; doi:10.1007/s10344-012-0646-y.

77. Kabigumila J. Sighting frequency and food habits of the leopard tortoise, Geochelone pardalis, in northern Tanzania. Afr J Ecol. 2001; doi:10.1046/j. 1365-2028.2001.00316.x.

78. Gautestad AO. Memory matters: Influence from a cognitive map on animal space use. J Theor Biol. 2011; doi:10.1016/j.jtbi.2011.07.010.

79. Le Maitre D, Colvin C, Maherry A. Water resources in the Klein Karoo: The challenge of sustainable development in a water-scarce area. S Afr J Sci. 2009; doi:10.1590/S0038-23532009000100019.

80. Serrai Z, Corrigan IM. Governance of fracking in Africa. Governance in Africa. 2015; doi:10.5334/gia.aj.

81. Academy of Science of South Africa. Academy of Science of South Africa. doi:10.17159/assaf.2016/0003

82. DWAF. Overview of water resources availability and utilisation. Pretoria: Department of Water Affairs and Forestry; 2003. Report number: P WMA16/ 000/00/0203.

83. Auffenberg W. A note on the drinking habits of some land tortoises. Anim Behav. 1963; doi:10.1016/0003-3472(63)90012-5.

84. Sinervo B. The sixth mass extinction is underway. In: The current reptile and amphibian biodiversity crisis compared to extinctions over the past 200 million years. Hangzhou: 8th World Congress of Herpetology; 2016.

85. McMaster MK, Downs CT. Do seasonal and behavioral differences in the use of refuges by the leopard tortoise (Geochelone pardalis) favor passive thermoregulation? Herpetologica. 2006; doi:10.1655/04-16.1.

\section{Submit your next manuscript to BioMed Central and we will help you at every step:}

- We accept pre-submission inquiries

- Our selector tool helps you to find the most relevant journal

- We provide round the clock customer support

- Convenient online submission

- Thorough peer review

- Inclusion in PubMed and all major indexing services

- Maximum visibility for your research

Submit your manuscript at www.biomedcentral.com/submit
Biomed Central 